\title{
CORRIGENDUM
}

\section{Myhre and LAPS syndromes: clinical and molecular review of 32 patients}

Caroline Michot, Carine Le Goff, Clémentine Mahaut, Alexandra Afenjar, Alice S Brooks, Philippe M Campeau, Anne Destree, Maja Di Rocco, Dian Donnai, Raoul Hennekam, Delphine Heron, Sébastien Jacquemont, Peter Kannu, Angela E Lin, Sylvie Manouvrier-Hanu, Sahar Mansour, Sandrine Marlin, Ruth McGowan, Helen Murphy, Annick Raas-Rothschild, Marléne Rio, Marleen Simon, Irene Stolte-Dijkstra, James R Stone, Yves Sznajer, John Tolmie, Renaud Touraine, Jenneke van den Ende, Nathalie Van der Aa, Ton van Essen, Alain Verloes, Arnold Munnich and Valérie Cormier-Daire

European Journal of Human Genetics (2014) 22, 1340; doi:10.1038/ejhg.2014.182

Correction to: European Journal of Human Genetics advance online publication, 15 January 2014; doi:10.1038/ejhg.2013.288

After the above article had been published online, it was brought to the authors' attention that Figure 1 contained an image for which the patient had not given his consent for publication. Figure 1 has therefore been replaced in this article. The authors would like to extend their sincere apologies for their error. 